\title{
Domiciliary nocturnal intermittent positive pressure ventilation in patients with respiratory failure due to severe COPD: long term follow up and effect on survival
}

\author{
S E Jones, S Packham, M Hebden, A P Smith
}

\begin{abstract}
Background-There is increasing interest in the use of non-invasive nocturnal intermittent positive pressure ventilation (NIPPV) in the management of patients with chronic hypercapnoeic (type II) respiratory failure. Although this treatment enables patients requiring mechanical ventilatory support to be treated more readily at home, few studies have been done to demonstrate its long term benefits in chronic obstructive pulmonary disease (COPD) and the application of NIPPV in these circumstances remains controversial.
\end{abstract}

Methods-Eleven patients in severe stable chronic type II respiratory failure due to COPD who were unresponsive to conventional treatments experienced symptomatic hypercapnia when receiving sufficient supplementary oxygen to result in an arterial oxygen saturation $\left(\mathrm{SaO}_{2}\right)$ of $\mathbf{7 9 0 \%}$. They were assessed for treatment with NIPPV, and its effects were observed for over two years using arterial blood gas tensions, spirometric parameters and body mass index (BMI), survival, hospital admissions, use of general practitioner resources, and patient satisfaction.

Results-Hospital admissions and GP consultations were halved after one year compared with the year before NIPPV and there was a sustained improvement in arterial blood gas tensions at 12 and 24 months when breathing air, despite progressive deterioration in ventilatory function. BMI did not change during the period of observation. The median survival was 920 days, with no patient dying within the first 500 days.

Conclusions-Domiciliary NIPPV results in improvements in arterial blood gas tensions which are sustained after two years of treatment and reduces both hospital admissions and general practitioner visits by patients with severe COPD in hypercapnoeic respiratory failure. It is well tolerated and, although there was no control group, survival appears to be prolonged when these results are compared with those of the NOTT and MRC (LTOT) trials.

(Thorax 1998;53:495-498)

Keywords: home ventilation; chronic obstructive pulmonary disease; outcome measures

Non-invasive positive pressure ventilation (NIPPV) is a well established form of treatment for chronic hypercapnoeic (type II) respiratory failure in patients with neuromuscular disease or skeletal deformity. Although there has been increasing interest in its use for patients in chronic type II respiratory failure due to chronic obstructive pulmonary disease (COPD), its use remains controversial in this group of patients with conflicting reports of its efficacy and acceptability. ${ }^{12}$

\section{Methods}

Eleven patients, all ex-smokers in severe type II respiratory failure, were electively admitted between 1991 and 1995. All were diagnosed as having COPD and were receiving maximal drug therapy. Long term oxygen therapy (LTOT) sufficient to correct hypoxaemia $\left(\mathrm{SaO}_{2}\right.$ $>90 \%$ ) resulted in symptomatic hypercapnia, especially morning headaches and excessive diurnal somnolence. Sleep apnoea syndrome was excluded (apnoea/hypnoea index $<10$ ) but patients 1, 3, 7, 8, 9, and 10 (table 1) experienced severe sleep hypoventilation.

Four patients (nos 2, 5, 6, and 8) had been intubated and ventilated on a total of seven occasions prior to NIPPV. All patients received supplementary oxygen. Seven were already on LTOT prior to NIPPV (mean 37 months) and continued with it, in addition to ventilation. Three further patients (nos 4, 6, and 7) were commenced on oxygen during the induction process. In one case (no. 4) NIPPV was accompanied by nocturnal oxygen therapy.

The pressure set, time cycled "Nippy" ventilator (Friday Medical, London) was used with nasal or full face masks (Respironics, Pennsylvania, USA and Friday Medical, London, UK). Settings were made initially according to patient comfort, then adjusted according to 
Table 1 Patient characteristics and pretreatment lung function

\begin{tabular}{|c|c|c|c|c|c|c|c|c|c|c|c|c|c|c|c|}
\hline Patient & $\operatorname{Sex}$ & Age & $B M I$ & $\begin{array}{l}F E V_{1} \% \\
\text { (l) }\end{array}$ & $\begin{array}{l}F V C \% \\
\text { (l) }\end{array}$ & $\begin{array}{l}T L C \% \\
\text { (l) }\end{array}$ & $\begin{array}{l}R V \% \\
\text { (l) }\end{array}$ & $\begin{array}{l}T_{L C O} \% \\
(\mathrm{ml} / \mathrm{min} / \mathrm{mm} \mathrm{Hg})\end{array}$ & $\begin{array}{l}\text { KCO } \\
(\mathrm{ml} / \mathrm{min})\end{array}$ & $\begin{array}{l}\mathrm{PaO}_{2} \\
(k P a)\end{array}$ & $\begin{array}{l}\mathrm{PaCO}_{2} \\
(\mathrm{kPa})\end{array}$ & $\begin{array}{l}\mathrm{PaCO}_{2} \text { with } \\
\text { corrected } \\
\mathrm{SaO}_{2}(\mathrm{kPa})\end{array}$ & $\begin{array}{l}-\mathrm{HCO}_{3} \\
m m o l / l\end{array}$ & $H C T$ & $\begin{array}{l}\text { Smoking } \\
\text { history } \\
\text { (pack years) }\end{array}$ \\
\hline 1 & $\mathrm{~F}$ & 63 & 56 & $\begin{array}{l}53 \\
(0.98)\end{array}$ & $69(1.7)$ & $\begin{array}{l}81 \\
(3.31)\end{array}$ & $\begin{array}{l}103 \\
(1.61)\end{array}$ & $72(14.1)$ & $\begin{array}{l}5.6 \\
(115 \%)\end{array}$ & 5.6 & 7.7 & 7.7 & 33 & 0.40 & 42 \\
\hline 2 & M & 73 & 30 & $\begin{array}{l}41 \\
(1.02)\end{array}$ & $50(1.8)$ & - & - & - & & 6.0 & 7.5 & 11.1 & 31 & - & 50 \\
\hline 3 & $\mathrm{M}$ & 67 & 29 & $\begin{array}{l}37 \\
(1.05)\end{array}$ & $\begin{array}{l}50 \\
(2.01)\end{array}$ & $\begin{array}{l}90 \\
(5.82)\end{array}$ & $\begin{array}{l}120 \\
(2.71)\end{array}$ & $88(22)$ & $\begin{array}{l}5.03 \\
(124 \%)\end{array}$ & 6.0 & 9.7 & 10.3 & 37 & 0.50 & 90 \\
\hline 4 & M & 65 & 42 & $\begin{array}{l}36 \\
(0.97)\end{array}$ & $\begin{array}{l}43 \\
(1.69)\end{array}$ & $\begin{array}{l}86 \\
(5.49)\end{array}$ & $\begin{array}{l}104 \\
(2.71)\end{array}$ & $94(25.3)$ & & 5.3 & 8.8 & 10.1 & 31 & 0.50 & 60 \\
\hline 5 & M & 62 & 26 & $\begin{array}{l}23 \\
(0.73)\end{array}$ & $\begin{array}{l}45 \\
(1.81)\end{array}$ & $\begin{array}{l}84 \\
(5.51)\end{array}$ & $\begin{array}{l}130 \\
(2.97)\end{array}$ & $70(18.6)$ & $\begin{array}{l}5.69 \\
(136 \%)\end{array}$ & 6.6 & 7.2 & 10.7 & 28 & 0.45 & 80 \\
\hline 6 & M & 72 & 26 & $\begin{array}{l}27 \\
(0.62)\end{array}$ & $\begin{array}{l}52 \\
(1.73)\end{array}$ & $\begin{array}{l}90 \\
(5.11)\end{array}$ & $\begin{array}{l}148 \\
(3.22)\end{array}$ & $60(12.7)$ & $\begin{array}{l}3.97 \\
(105 \%)\end{array}$ & 6.5 & 10.8 & 11.7 & 34 & 0.48 & 18 \\
\hline 7 & $\mathrm{~F}$ & 48 & 42 & $\begin{array}{l}43 \\
(1.02)\end{array}$ & $\begin{array}{l}66 \\
(1.97)\end{array}$ & $\begin{array}{l}97 \\
(4.5)\end{array}$ & $\begin{array}{l}158 \\
(2.52)\end{array}$ & $71(16.4)$ & $\begin{array}{l}5.70 \\
(109 \%)\end{array}$ & 6.4 & 8.3 & 6.7 & 30 & 0.41 & 23 \\
\hline 8 & $\mathrm{~F}$ & 45 & 23 & $\begin{array}{l}20 \\
(0.44)\end{array}$ & $\begin{array}{l}45 \\
(1.19)\end{array}$ & $\begin{array}{l}90 \\
(3.6)\end{array}$ & $\begin{array}{l}158 \\
(2.07)\end{array}$ & $90(19.8)$ & $\begin{array}{l}8.20 \\
(155 \%)\end{array}$ & 5.3 & 8.0 & 8.0 & 33 & 0.46 & 45 \\
\hline 9 & M & 66 & 33 & $\begin{array}{l}47 \\
(1.26)\end{array}$ & $\begin{array}{l}61 \\
(2.32)\end{array}$ & $\begin{array}{l}100 \\
(6.3)\end{array}$ & $\begin{array}{l}143 \\
(3.2)\end{array}$ & $80(19.8)$ & $\begin{array}{l}4.30 \\
(107 \%)\end{array}$ & 7.7 & 7.3 & 7.5 & 32 & 0.49 & 200 \\
\hline 10 & M & 48 & 34 & $\begin{array}{l}34 \\
(1.19)\end{array}$ & $\begin{array}{l}58 \\
(2.68)\end{array}$ & $\begin{array}{l}91 \\
(6.3)\end{array}$ & $\begin{array}{l}150 \\
(3.3)\end{array}$ & $80(24.5)$ & $\begin{array}{l}5.90 \\
(124 \%)\end{array}$ & 7.7 & 7.3 & 8.0 & 33 & 0.55 & 55 \\
\hline 11 & M & 51 & 26 & $\begin{array}{l}19 \\
(0.60)\end{array}$ & $44(1.9)$ & $\begin{array}{l}100 \\
(6.4)\end{array}$ & $\begin{array}{l}195 \\
(4.02)\end{array}$ & $32(8.9)$ & $\begin{array}{l}2.10 \\
(46 \%)\end{array}$ & 4.6 & 8.4 & 8.4 & 40 & 0.47 & 60 \\
\hline Mean v & alues & 60 & 33.3 & 34.5 & 53 & 82.6 & 128 & 67 & 4.2 & 6.02 & 8.08 & 9.12 & 32.9 & 0.42 & 65.7 \\
\hline
\end{tabular}

$\mathrm{FEV}_{1}=$ forced expiratory volume in one second; FVC = forced vital capacity; TLC = total lung capacity; RV = residual volume; TLCO = carbon monoxide transfer factor; $\mathrm{KCO}=$ carbon monoxide transfer coefficient; $\mathrm{PaO}_{2}, \mathrm{PaCO}_{2}=$ arterial oxygen and carbon dioxide tensions.

diurnal $\mathrm{PaCO}_{2}$ values. During induction of treatment pulse oximetry and arterial blood gas tensions were regularly measured. Once respiratory variables had been stabilised and the patients were acclimatised, they were discharged and reviewed in the multidisciplinary sleep and breathing clinic.

Morbidity was assessed from a review of the general practitioner records. Consultations for respiratory reasons, general problems and home visits were recorded, together with hospital admissions in the year before and the year after starting NIPPV.

Patient compliance with NIPPV (number of nights/hours per night), experience of symptoms of hypercapnia since commencing NIPPV, side effects of mask ventilation, and overall satisfaction with the treatment were assessed by means of a locally developed postal questionnaire after two years of treatment. Patients were asked to respond on a scale of severity - for example, often/sometimes/never; every night/most nights/rarely.

To assess the effect of NIPPV on gas exchange the best blood gas measurements when spontaneously breathing air were taken in the month prior to starting NIPPV, and the worst (in the event of more than one measurement being available) at six, 12 and 24 month intervals after starting the treatment.

Spirometric testing, using a Vitalograph dry bellows spirometer, was repeated 12 and 24 months after commencing NIPPV. Body mass index (BMI) was calculated for the period before and six, 12, and 24 months after starting NIPPV. Lung volumes were measured using the multibreath helium dilution technique and carbon monoxide transfer factor using the single breath technique. ${ }^{3}$

STATISTICAL ANALYSIS

Comparisons were made of values before and after commencing NIPPV. Analysis of variance (Freidman non-parametric ANOVA) and paired $t$ tests were used to examine differences between these two periods in terms of blood gas tensions, lung function, admissions to hospital, use of general practitioner resources, and body mass index. The results of parametric measurements are presented as mean (SD), mean difference, $95 \%$ confidence interval, and statistical probability.

\section{Results}

ARTERIAL BLOOD GAS TENSIONS

Individual patient data are shown in table 1, all whilst breathing air spontaneously: $\mathrm{PaO}_{2}$ improved from a mean (SD) of $6.0 \mathrm{kPa}(0.97)$ prior to NIPPV to 7.5 (1.2), (mean difference $1.5,95 \%$ CI 0.56 to $2.57, \mathrm{p}=0.006)$ at $\operatorname{six}$ months, 7.8 (1.2) $\mathrm{kPa}$ (mean difference 1.78, $95 \%$ CI 0.69 to $2.8, \mathrm{p}=0.004$ ) at 12 months, and $7.2(1.1) \mathrm{kPa}$ at 24 months (mean difference $1.27,95 \%$ CI 0.42 to $2.12, \mathrm{p}=$ 0.003).

$\mathrm{PaCO}_{2}$ fell from a mean (SD) value of 8.1 (1.3) $\mathrm{kPa}$ to $6.4(1.2)$ (mean difference -1.73 , $95 \% \mathrm{CI}-3.15$ to $-0.32, \mathrm{p}=0.021)$ at $\mathrm{six}$ months, $6.40 \quad(1.1) \mathrm{kPa}$ (mean difference $-1.66,95 \% \mathrm{CI}-3.04$ to $-0.28, \mathrm{p}=0.023)$ at 12 months, and $6.7(0.9) \mathrm{kPa}$ at 24 months (mean difference $-1.35,95 \% \mathrm{CI}-2.59$ to $-0.11, \mathrm{p}=$ 0.03).

Plasma bicarbonate concentration fell from a mean (SD) of 33 (3.3) mmol/l before NIPPV to 29 (3.7) $\mathrm{mmol} / \mathrm{l}$ at six months (mean difference $-3.64,95 \%$ CI -7.27 to -0.002$), 29$ (3.9) $\mathrm{mmol} / \mathrm{l}$ at 12 months (mean difference $-3.63,95 \%$ CI -7.11 to -0.17 ), and 30 (3.8) $\mathrm{mmol} / \mathrm{l}$ at two years (mean difference $-2.7,95 \%$ CI -6.46 to 1.06$)$. These results were not statistically significant.

SURVIVAL

Two patients died, one (patient 4) after 820 days and the other (patient 5) after 1522 days of NIPPV treatment, both of acute respiratory failure. Median survival is 920 days (range 686-1240). 
SPIROMETRIC DATA

During the year following NIPPV, FEV, decreased from a mean (SD) of 34 (11.2)\% predicted to 27 (8.9) \% (mean difference -7.09 , $95 \% \mathrm{CI}-12.06$ to $-2.12, \mathrm{p}=0.012)$, and in the second year further to $26(9.9) \%$ predicted (mean difference $-9.09,95 \%$ CI -15.79 to $-2.39, \mathrm{p}=\mathrm{NS}$ ), and FVC decreased from a mean of $53(9.2) \%$ predicted to $49(13.0) \%$ (mean difference $-3.45,95 \% \mathrm{CI}-13.5$ to 6.59 , $\mathrm{p}=0.01)$. During the first year the $\mathrm{FEV}_{1} / \mathrm{FVC}$ ratio fell from $47 \%$ predicted to $41 \%$ predicted $(p=0.016)$, and to $39 \%$ at the end of the second year $(\mathrm{p}=\mathrm{NS})$.

HOSPITAL ADMISSIONS

The median number of admissions to hospital before NIPPV was two per year (range 0-5); the median difference in admissions to hospital before and after NIPPV was 1.00 (95\% CI 0 to 2 ). The duration of stay in hospital decreased from a median of 16 days (range 0-47) to 7 days (range $0-15), p=0.023$, median difference 1.00 (95\% CI for median difference 2 to 25 ).

GENERAL PRACTITIONER RESOURCES

"General" consultations at the GP surgery per year fell following NIPPV, although this was not statistically significant (median difference $4.0,95 \%$ CI -1.0 to 10 ). "Respiratory" consultations were also reduced (median difference $3.0,95 \%$ CI -1 to 8.0 ) after commencing NIPPV, as were house calls (median difference $1.0,95 \% \mathrm{CI}-1.0$ to 7.0 ). Patients on NIPPV were supported by the clinical nurse specialist and a telephone contact number was made available. No patient requested a home visit; a mean of 1.4 visits were initiated by the specialist nurse in the first year.

PATIENT SATISFACTION AND COMPLIANCE

Of the patients who fulfilled the criteria for NIPPV none withdrew from treatment. After two years patients were using NIPPV for an average of 6.5 hours each night. All patients had experienced relief of morning headache and excessive diurnal somnolence, and claimed improved sleep quality. There was no improvement in breathlessness; $75 \%$ claimed to be "very satisfied" with the treatment, and dissatisfaction in the remainder was related to skin ulceration on the bridge of the nose caused by the mask, a problem which was resolved in most cases by careful adjustment of the head harness.

There was no significant change in BMI or haematocrit levels before and after commencing NIPPV.

\section{Discussion}

We describe a group of patients with COPD in whom the use of LTOT was associated with symptomatic hypercapnia. They tended towards obesity which resulted in lung compression, as evidenced by the raised $\mathrm{KCO}_{\mathrm{CO}}$ and this probably contributed to the tendency to hypoventilate, especially during sleep. All had severe airways obstruction. Improvement in blood gas measurements during the period of treatment cannot be attributed to weight reduction.

Treatment with NIPPV resulted in a marked improvement in blood gas tensions and in symptoms, and a striking reduction in the frequency and length of admissions, GP consultations, and house calls. The reduction in the use of resources was not simply due to transfer of care to the respiratory nurse specialist. Most admissions were for adjustment of ventilator pressures and were of short duration whereas previously they were for treatment of ventilatory failure. These outcomes were sustained for the two year period of observation, despite gradually worsening ventilatory function.

In terms of severity of ventilatory function and respiratory failure, the patients were comparable to those in the MRC (LTOT) ${ }^{4}$ and NOTT $^{5}$ series although insufficient data are available to make comparisons of $\mathrm{BMI}$ or lung mechanics. In those series the mean $\mathrm{PaO}_{2}$ and $\mathrm{PaCO}_{2}$ were $6.7 \mathrm{kPa}$ and $7.3 \mathrm{kPa}$, and $6.8 \mathrm{kPa}$ and $5.8 \mathrm{kPa}$, respectively. A mean $\mathrm{FEV}_{1}$ of 0.98 litres ( $37 \%$ predicted) in our patient group compares with 0.76 litres in the MRC trial and $29.5 \%$ predicted in the NOTT trial, and mean age and sex were similar. In the MRC (LTOT) trial about $45 \%$ of patients had died at three years, some $30 \%$ in the first 500 days whereafter the mortality fell to about $12 \%$ each year in the treated group. In the NOTT trial about $12 \%$ had died in the first 12 months, and $22 \%$ at two years. Those patients whose $\mathrm{SaO}_{2}$ fell below $85 \%$ during sleep were at particular risk. Although arterial blood gas tensions of the patients in this series were more severely impaired, survival was considerably improved compared with those trials despite deteriorating pulmonary function. Although this is a group with a poor prognosis, ${ }^{6}$ no patient died during the first two years of treatment. The median survival was 920 days (the longest surviving for over four years), suggesting that intervention with NIPPV had a significant impact on survival.

Because there was no survival benefit until after 500 days (in men), the MRC trial suggested that patients with advanced disease might not be salvageable. The extended survival of our patients, however, lends support to the idea that NIPPV is an adjunct that should be considered in all cases of chronic type II respiratory failure unresponsive to LTOT, particularly where there is evidence of worsening hypoventilation during sleep. Addition of NIPPV to LTOT improves quality of life. ${ }^{7}$ LTOT alone does not, ${ }^{8}$ nor does it reduce the frequency of hospital admission.

Previous reports of the effects of NIPPV in type II respiratory failure due to chronic airways obstruction over shorter follow up periods have produced similar results, but not all patients in this category will respond so well. ${ }^{9}{ }^{10}$ Elliott et $a l^{11}$ found that only seven out of 12 patients continued with treatment over 12 months. Those who did so had fewer symptoms (so may not have perceived the benefit), and others did so because of loss of confidence in equipment and possibly lack of training. We agree with Meecham Jones et al that these 
patients take to their new treatment much more readily if they are stabilised during a period in hospital when the beneficial effects on excessive diurnal somnolence and intellectual function can be definitively demonstrated. Specialised nursing and medical support appears to be essential.

Domiciliary NIPPV produces significant and sustained improvements in arterial blood gas tensions in patients with severe COPD and hypercapnoeic respiratory failure unresponsive to other treatments, reducing both hospital admissions and demand on general practitioner resources. Although the number of patients is small, the encouraging results of treatment suggest that prospective studies with clearly defined enrolment criteria in a larger group of patients are urgently required.

The authors acknowledge the assistance of Dr Abdullah Eid with statistical analysis.

1 Schneerson JM. The changing role of mechanical ventilation in COPD. Eur Respir F 1996;9:393-8.

2 Leger P, Bedicam J-M, Cornette A, et al. Nasal intermittent positive pressure ventilation: long term follow-up in patients in severe chronic respiratory failure. Chest 1994;105:100-5.

3 Cotes JE. Lung function. 3rd ed. Oxford: Blackwell, 1975.

4 Report of the Medical Research Council Working Party. Long term domiciliary oxygen therapy in chronic hypoxic cor pulmonale complicating chronic bronchitis and emphysema. Lancet 1981;i:681-6.

5 Nocturnal Oxygen Therapy Trial Group. Continuous or nocturnal oxygen therapy in hypoxaemic chronic obstructive airway disease. Ann Intern Med 1980;93:391-8.

6 Anthonisen NR, Wright EZ, Hodgkin JE, and the IPPB Trial Group. Prognosis in chronic obstructive pulmonary disease. Am Rev Respir Dis 1986;133:17-20.

7 Meecham Jones DJ, Paul EA, Jones PW, et al. Nasal pressure support ventilation plus oxygen compared with oxygen therapy alone in hypercapnoeic COPD. Am $\mathcal{f}$ Respir Crit Care Med 1995;152:538-44.

8 Okubadejo AA, Paul EA, Jones PW, et al. Does long term oxygen therapy affect quality of life in patients with severe chronic obstructive airway disease and severe hypoxaemia? Eur Respir 7 1996;9:2335-9.

9 Strumpf D, Millman R, Carlisle C, et al. Nocturnal positive pressure ventilation via nasal mask in patients with severe pressure ventilation via nasal mask in patients with severe
chronic obstructive pulmonary disease. Am Rev Respir Dis chronic obstructive

10 Meecham Jones DJ, Wedzicha JA. Non invasive positive pressure ventilation in advanced progressive chronic respiratory failure due to COPD. Am Rev Respir Dis 1993;147: A322.

11 Elliot MW, Simonds AC, Carroll MP, et al. Domiciliary nocturnal nasal intermittent positive pressure ventilation in hypercapnoeic respiratory failure due to chronic obstrucive hypercapnoeic respiratory failure due to chronic obstrucive
airway disease: effects on sleep and quality of life. Thorax 1992;47:342-8.

Thorax; 1998;53:498-500

\section{Evidence for eosinophil activation in bronchiectasis unrelated to cystic fibrosis and bronchopulmonary aspergillosis: discrepancy between blood eosinophil counts and serum eosinophil cationic protein levels}

Claus Kroegel, Marc Schüler, Martin Förster, Ruedi Braun, Paul Reinhard Grahmann normal controls (7.5 $\mu \mathrm{g} / \mathbf{1}(3.5-19) ; \mathrm{p}<0.003)$. In contrast, significantly increased peripheral eosinophil numbers were observed in patients with bronchial asthma $\left(305 \times 10^{6} / 1\right.$; $\mathrm{p}<0.01)$ but not in those with bronchiectasis $\left(10^{2} \times 10^{6} / 1\right)$, COPD $\left(117 \times 10^{6} / 1\right)$, and healthy controls $\left(101 \times 10^{6} / 1\right)$.

Conclusions-The discrepancy between eosinophil counts and eosinophil numbers in patients with bronchiectasis suggests that serum ECP levels may be more relevant in assessing local eosinophil involvement than blood eosinophil numbers. (Thorax 1998;53:498-500)

Keywords: bronchiectasis; asthma; chronic obstructive pulmonary number; eosinophil cationic protein

Bronchiectasis is associated with a vigorous bronchial inflammation due to frequent or persistent bacterial colonisation and increased numbers of neutrophils and neutrophil-derived products found in both bronchoalveolar lavage

Abstract

Background-Increased serum levels of been detected in adost patients cystic fibrosis. However, ECP concen unrelated to cystic fibrosis have not Methods-Eosinophil numbers and serum 14 patients with known or newly diagnosed bronchiectasis and compared with age and chial asth monary disease could be excluded. chiectasis (median (range) $22.5 \mu \mathrm{g} / 1$ (7-85)) and allergic asthma (35.0 $\mu \mathrm{g} / 1$ (7-128))
\end{abstract} M Förster

R Braun

P R Grahmann

Pneumology, Medical
Clinic IV, Friedrich-

Schiller-University,

D-7740 Jena, Germany

C Kroegel

Dre 
(BAL) fluid and histological specimens during the course of infection. ${ }^{1}$ Unlike neutrophils, eosinophils in BAL fluid and affected bronchoalveolar tissue have been detected in small numbers only. ${ }^{2}$ However, three recent reports ${ }^{3-5}$ have described increased levels of the eosinophil cationic protein (ECP) in the sputum and/or serum, indicating that eosinophils and their products may also contribute to the inflammatory process in cystic fibrosis. Since no data are available for subjects with bronchiectasis unrelated to cystic fibrosis, we prospectively assessed the serum ECP concentrations and blood leucocyte counts in adult patients admitted to our clinic in whom bronchiectasis had been previously established or subsequently diagnosed.

\section{Methods}

PATIENTS AND CONTROLS

Between January 1992 and August 1994, 14 consecutive patients (eight men) with previously proven or newly diagnosed bronchiectasis seeking medical advice in the Department of Pneumology were included in the study. The patients were selected on the basis of (1) a history of persistent cough, (2) recurrent pneumonias and frequent haemoptysis, (3) large quantities and partially foul purulent sputum production, (4) persistently positive sputum cultures for more than three years, and (5) radiological evidence of bronchiectasis detected either by bronchography $(n=8)$ and/or high resolution computed tomographic (CT) scanning $(\mathrm{n}=12)$. All patients had localised bronchiectases confined to one or two lobes.

The definite cause of bronchiectasis could not be found. None of the patients reported a family history of similar lung disease. In addition, hereditary diseases, including ciliary immotility syndrome, $\alpha_{1}$-antitrypsin deficiency, and cystic fibrosis as well as both IgG and IgA deficiency were ruled out, suggesting that the bronchiectasis was most probably acquired.

In 10 patients, infection with one or more of Pseudomonas aeruginosa, Streptococcus pneumoniae or Haemophilus influenzae was established by sputum culture. Candida spp were observed in the sputum of three patients. There was no clinical and serological evidence for viral infection or bronchopulmonary aspergillosis during the time of evaluation. In addition, sputum cultures did not reveal Aspergillus organisms or other fungi, and dermal hypersensitivity to Aspergillus antigen was absent. In two patients the total serum IgE levels were slightly above the upper normal limit (124 and $187 \mathrm{U} / \mathrm{l}$ ). However, neither elevated specific IgE nor a positive skin test for common allergens, including grass pollen, birch pollen, and house dust mite, were found in these patients. In addition, no history of intermittent wheezing, chest tightness, and no family history of atopic diseases were present. None of the patients had received steroids or antibiotic treatment during the four weeks prior to admission.

The 14 adult patients (mean age 54.8 years; range 31-78) with bronchiectasis were compared with three sex and age matched control groups consisting of 14 patients each with
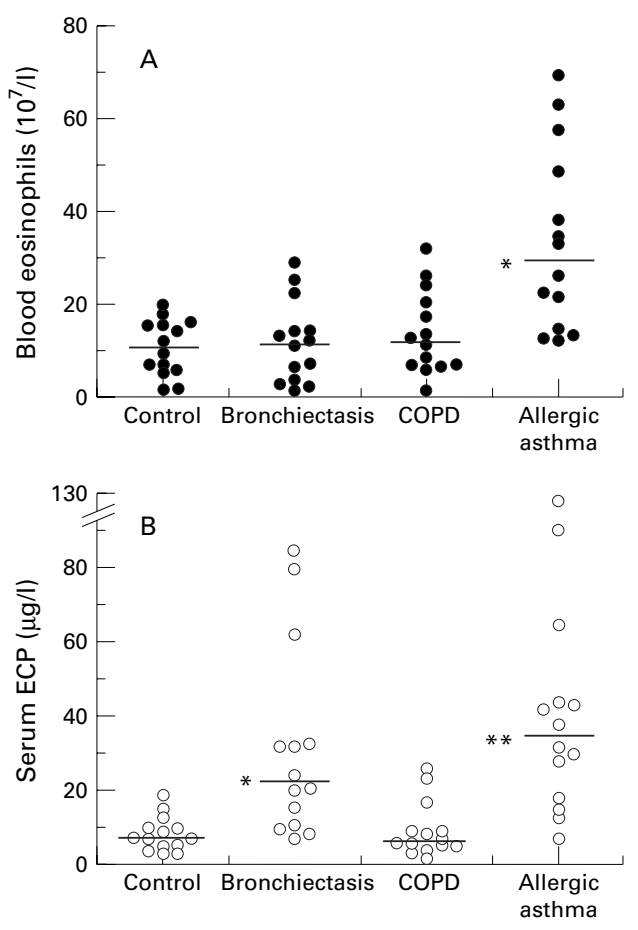

Figure 1 (A) Absolute blood eosinophil counts and (B) serum ECP concentrations in 14 patients with bronchiectasis compared with age and sex matched control groups. Data given are individual cell counts. Bars indicate median values.

either previously established allergic asthma, chronic obstructive pulmonary disease (COPD), or healthy controls in whom pulmonary disease was excluded. Asthma and COPD were diagnosed according to the criteria published previously. ${ }^{6}$ All patients were without clinical signs of a current infectious exacerbation during the previous four weeks. Informed consent for blood sampling was obtained in all cases. All subjects underwent a thorough clinical examination and lung function was assessed using whole body plethysmography.

BLOOD SAMPLING AND ECP MEASURMENTS

Venous blood samples were collected at routine sampling for clinical evaluation and left at room temperature for 60 minutes as recommended by the manufacturers. After centrifugation at $1000 \mathrm{~g}$ for 10 minutes at $4^{\circ} \mathrm{C}$, plasma was frozen and stored at $-20^{\circ} \mathrm{C}$ until further use. $^{7}$ ECP was measured using a double antibody radioimmunoassay (Pharmacia, Uppsala, Sweden) (coefficient of variation $8.5 \%$ ). In addition, total leucocyte counts were measured using standard cytometry (coefficient of variation $7.4 \%$ ).

\section{STATISTICAL ANALYSIS}

The two tailed Mann-Whitney $U$ test and Kruskal-Wallis test were used to compare values in two or more groups, respectively. Correlations between continuous variables were calculated using Spearman's rank test.

\section{Results}

Total blood leucocyte counts were similar between all groups, with median values ranging 
from $6.5 \times 10^{9} / 1$ (controls) to $7.1 \times 10^{9} / 1$ (asthmatics). In addition, similar counts of neutrophils were observed ranging from 3.9 to $13.2 \times 10^{9} / 1$ with the highest median of $5.4 \times$ $10^{9} / 1\left(5.3-24 \times 10^{9} / 1\right)$ in patients with bronchiectasis followed by allergic asthmatic patients $\left(4.3 \times 10^{9} / 1 ; 1.4-7.3 \times 10^{9} / 1\right)$, controls $(4.1$ $\left.\times 10^{9} / 1 ; 3.3-7.2 \times 10^{9} / 1\right)$, and patients with COPD $\left(3.8 \times 10^{9} / 1 ; 3.5-12.8 \times 10^{9} / 1\right)$. Total leucocyte numbers and neutrophil counts were not statistically different between the groups studied ( $p>0.05)$.

TOTAL PERIPHERAL BLOOD EOSINOPHIL COUNTS Blood eosinophil numbers in patients with bronchiectasis ranged from 1 to $32 \times 10^{7} / 1$ with a median of $10.2 \times 10^{7} / 1$ (fig $1 \mathrm{~A}$ ), and were not different from either controls $\left(10.1 \times 10^{7} / 1\right.$; range 1.6-21.4) or patients with COPD (11.7 $\times 10^{7} / 1$; range $0.6-31.5$ ) (fig $1 \mathrm{~A}$ ). However, significantly raised eosinophil counts were observed in the blood of subjects with allergic asthma $\left(30.5 \times 10^{7} / 1\right.$; range $\left.12.3-69.3\right)$ compared with that of other groups (all $\mathrm{p}<0.05)$.

SERUM ECP CONCENTRATIONS

Serum ECP levels in the healthy control group ranged from 3.5 to $19 \mu \mathrm{g} / 1$ (median $7.5 \mu \mathrm{g} / \mathrm{l}$ ), which is close to the ECP concentrations observed in patients suffering from COPD (1.5-28 $\mu \mathrm{g} / \mathrm{l}$; median $6.7 \mu \mathrm{g} / \mathrm{l}$ ) (fig 1B). Patients with allergic asthma showed significantly raised serum ECP levels, ranging from 7 to $128 \mu \mathrm{g} / 1$ with a median of $35.0 \mu \mathrm{g} / 1 \quad(\mathrm{p}<0.001$ versus both controls and patients with COPD). In contrast to the eosinophil numbers, all except two subjects with bronchiectasis showed an increase in serum ECP concentration equal to or above the median concentration measured within the control and COPD groups. The median ECP value of $22.5 \mu \mathrm{g} / 1$ (range $7-85$ $\mu \mathrm{g} / \mathrm{l})$ for patients with bronchiectasis was significantly higher than that of control subjects $(p<0.003)$ or subjects with COPD $(\mathrm{p}<0.006)$. In contrast, no difference was detected between ECP serum levels in patients with bronchiectasis or bronchial asthma $(p>0.05)$. In addition, no correlation was found between eosinophil counts and ECP levels among control subjects $\left(r^{2}=0.09\right.$; $\mathrm{p}>0.05)$, asthmatics $\left(r^{2}=0.002 ; \mathrm{p}>0.05\right)$, and patients suffering from bronchiectasis $\left(r^{2}=\right.$ $0.02 ; \mathrm{p}>0.05)$ or COPD $\left(r^{2}=0.001 ; \mathrm{p}>0.05\right)$.

\section{Discussion}

The present study provides evidence that adult patients with bronchiectasis unrelated to either cystic fibrosis or bronchopulmonary aspergillosis show significantly increased serum ECP levels compared with sex and age matched controls and patients suffering from COPD. The magnitude of ECP values associated with bronchiectasis was similar to the concentrations measured in the serum of allergic asthmatic subjects. However, in contrast to patients with bronchial asthma, blood eosinophil counts in those with bronchiectasis were not increased above those obtained from normal controls or patients with COPD. Finally, the number of peripheral neutrophils was not different among the four groups studied.

To our knowledge, raised serum ECP in adult patients with bronchiectasis has not been previously described, and the reason for this observation in the absence of elevated blood eosinophil counts remains unclear. Possibly, secondary allergic sensitisation observed in bronchiectasis may have caused the increased ECP levels observed. ${ }^{1}$ However, none of the patients with bronchiectasis had a positive skin test or raised allergen specific IgE levels against common allergens. Thus, although we cannot totally exclude the possibility that a subclinical allergic component in our patients may have contributed to the increase in ECP levels, it appears unlikely to represent a dominant factor.

A central finding of our study is the discrepancy between the raised serum ECP levels and the number of blood eosinophils in patients with bronchiectasis, which were not different to those of the controls or patients with COPD. In subjects with allergic asthma, however, both serum ECP concentrations and eosinophil counts were significantly above the normal range, which is in good agreement with previous published studies. ${ }^{8}$ Though the reasons for the apparent discrepancy between raised ECP levels and normal eosinophil counts remain to be elucidated, data reported by Koller et al in adolescent subjects with cystic fibrosis suggest that peripheral eosinophils may be in a preactivated state, possibly due to the action of circulating mediators such as cytokines. However, future studies assessing serum cytokine concentrations from patients with bronchiectasis are required to substantiate this hypothesis.

In summary, together with previously published studies, ${ }^{3-5}$ the present data suggest that eosinophil derived granular proteins are increased in patients with lung disorders associated with bronchiectatic tissue destruction despite normal eosinophil counts. We therefore conclude that ECP does not merely reflect the absolute number of eosinophils but represents a more meaningful indicator for eosinophil participation in disease.

This work was supported by the County of Thüringia, Germany (01KC8906/1).

1 Moreschi MA, Fiel SB. An update on bronchiectasis. Curr Opin Pulmon Med 1995;1:119-24.

2 Azzawi M, Johnston PM, Majumdar S, et al. T lymphocytes and activated eosinophils in airway mucosa in fatal asthma and cystic fibrosis. Am Rev Respir Dis 1992;145:1477-82.

3 Koller DY, Götz M, Eichler I, et al. Eosinophil activation in cystic fibrosis. Thorax 1994;49:496-9.

4 Reimert CM, Giwercman B, Hoiby N, et al. Eosinophil cationic protein in sputum from cystic fibrosis patients with Pseudomonas aeruginosa infections. Lancet 1994;344: with Pse4-5.

5 Koller DY, Urbanek R, Götz M. Increased degranulation of eosinophil and neutrophil granulocytes in cystic fibrosis. Am f Respir Crit Care Med 1995;152:629-33.

6 American Thoracic Society. Standards for the diagnosis and care of patients with chronic obstructive pulmonary diases (COPD) and asthma. Am Rev Respir Dis 1987;136:225-44. 7 Venge P, Roxin LE, Olsson I. Radioimmunoassay of human eosinophil cationic protein. Br F Haematol 1977;37:331-6. 8 Griffin E, Hakansson L, Formgren H, et al. Blood eosinophil number and activity in relation to lung function in patients with asthma and eosinophilia. F Allergy Clin Immunol 1991; 87:548-57. 